\title{
Deciphering the Impact of Water-stress on Plant Growth and Yield Attributes in Tomato Genotypes
}

\author{
Reeva Singh ${ }^{1 *}$, Vaishali ${ }^{1}$, Rakesh S Sengar ${ }^{1}$, Mukesh Kumar ${ }^{1}$, Bijendra Singh ${ }^{2}$ and \\ Pooran Chand ${ }^{3}$
}

\begin{abstract}
${ }^{1}$ Department of Biotechnology, College of Agriculture, Sardar VallabhBhai Patel University of Agriculture and Technology, Meerut, India

${ }^{2}$ College of Horticulture, Sardar VallabhBhai Patel University of Agriculture and Technology, Meerut, India

${ }^{3}$ Department of Genetics and Plant Breeding, College of Agriculture, Sardar VallabhBhai Patel University of Agriculture and Technology, Meerut, India
\end{abstract}

*Corresponding author: reeva.chahal@gmail.com (ORCID ID: 0000-0002-8983-7557)

Paper No. 932

Received: 14-06-2021

Revised: 29-08-2021

Accepted: 06-09-2021

\begin{abstract}
The adverse effect of water-stress on growth and yield parameters of tomato (Solanum lycopersicum) genotypes viz., plant height, days to $50 \%$ flowering, number of branches per plant, number of flower per truss, number of flower truss per plant and fruit setting percentage was investigated under field conditions in rainout shelter. The drought condition was imposed 25 days after transplanting by withhold water supply. Experimental trial was carried out with nine genotypes adopting complete randomized design (CRD) with three replications and two treatments viz., well-watered and withhold water supply. The water-stress caused reduction in all plant growth and yield parameters. The genotypes Arka Vikas showed significantly less reduction in plant height, number of flower per truss and number of flower truss per plant, while EC179083 showed minimum reduction in days to 50\% flowering, number of branches per plant and fruit setting percentage during drought so both genotypes were considered as drought tolerant. Genotypes EC160885 and EC 249508 represented the maximum reduction in all morphological parameters among all genotypes, hence considered as drought susceptible.
\end{abstract}

\section{HIGHLIGHTS}

(0 Effect of water stress on growth and yield attributes of tomato genotypes

0 Identifying best genotype among unexplored and explored tomato genotypes under water stress conditions.

Keywords: tomato genotypes, drought, plant height, days to 50\% flowering, fruit setting percentage

Tomato (Solanum lycopersicum L.) is the second most important fruit or vegetable crop next to potato (Solanum tuberosum L.), with approximately 180.7 million tons of tomato fruits produced on 50.31 million hactare each year (FAOSTAT, 2020). Asia accounts for $61.1 \%$ of global tomato production, while Europe, America, and Africa produced $13.5 \%, 13.4 \%$, and $11.8 \%$ of the total tomato yield, respectively. It is one of the most popular and widely consumed vegetable crops all over the world. Tomato has been recently gaining attention in relation to the prevention of some human diseases. The nutritional importance of tomatoes is largely explained by their various health-promoting compounds, including vitamins, carotenoids, and phenolic compounds (Li et al. 2018). The bioactive compounds have a wide range of physiological properties, including

How to cite this article: Singh, R., Vaishali, Sengar, R.S., Kumar, M., Singh, B. and Chand, P. 2021. Deciphering the Impact of Water-stress on Plant Growth and Yield Attributes in Tomato Genotypes. IJAEB, 14(03): 461-467.

Source of Support: None; Conflict of Interest: None (क) क्ष 
anti-inflammatory, anti-allergenic, antimicrobial, vasodilatory, antithrombotic, cardio-protective, and antioxidant effects (Raiola et al. 2014). Particularly lycopene, which is an unsaturated alkylic compound, appears to be an active compound in the prevention of cancer, cardiovascular risk and in slowing down cellular aging (Gerster 1997).

Tomato production is challenged by several problems around the world, including the scarcity of water resources, soil salinization, and other abiotic stresses (Fahad et al. 2017; Zhou et al. 2019). Drought stress can affect plant growth, development and yield. It has been estimated that up to $45 \%$ of world agricultural lands are subjected to drought (Bot et al. 2000). Its cultivation is mainly concentrated in semiarid zones, like the Mediterranean, where it needs to be cultivated under irrigation (Rivelli et al. 2013), and where drought events associated with climate change are expected to be more frequent (Nankishore and Farrell 2016). Thus, water shortage caused by drought periods can have important consequences for tomato production, and might produce yield reduction up to $50 \%$ in case of equivalent reduction in irrigation (Cantore et al. 2016).

The challenges of abiotic stress on plant growth and development are emerging ecological impacts of climate change and thus constraints to crop production. These constraints towards global food supply and a balanced environment encourage research and development of climate-smart crops, resilient to climate change (Pereira 2016). Both vegetative and reproductive processes of modern tomato cultivars can be severely compromised by drought stress, which inhibits seed development, reduces vegetative growth and compromises reproduction (Bartels and Sunkar 2005; Nuruddin et al. 2003).

Therefore, the present investigation was undertaken with the aim of characterizing and assessing morphological variability of tomato genotypes collected from diverse sources. In this study, morphological characters such as plant height, days to $50 \%$ flowering, number of flower truss ${ }^{-1}$, number of flower truss plant ${ }^{-1}$ and fruit setting percentage were used to distinguish the tomato genotypes response to water limiting conditions.

\section{MATERIALS AND METHODS}

\section{Experiment location and weather data}

The experiment was conducted at a research field under rain out shelter of Field Laboratory and Experiment Station under Department of Agricultural Biotechnology, SVPUA\&T, Meerut, India, during Rabi season (2019-2020). The experimental site located in the semi-arid environment and agroclimatic plain zone of Uttar Pradesh state lies at North West Plain Zone, India, $28.99^{\circ} \mathrm{N}$ latitude and $77.7^{\circ} \mathrm{E}$ longitude with an altitude of $220 \mathrm{~m}$ above the mean sea level. The climate of the experimental site is sub-tropical and having extreme weather conditions, i.e., extremely hot summer and cold winter. The meteorological data were recorded by an automatic weather station of Indian Institute of Farming System and Research (IIFSR), Modipuram, Meerut, India. Graphical representation of weather data are shown in Fig. 1.

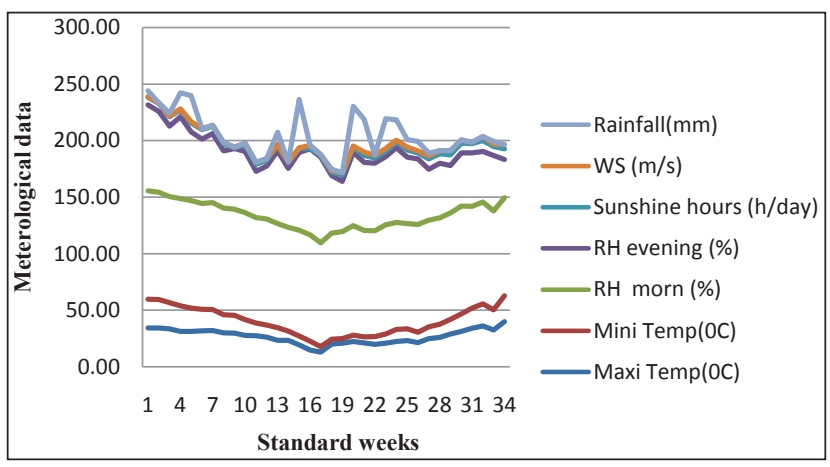

Fig. 1: Meteorological variables during experimental field trial

\section{Experimental design}

Nine tomato germplasms were procured for the study (Table 1), out of which, five genotypes procured from ICAR-National Bureau of Plant Genetic resources (ICAR-NBPGR), New Delhi while others were released varieties.

Seeds of each genotype were sown for nursery preparation in mid September in medium sized germination trays having mixture of cocopeat and vermicompost. Twenty five days old seedlings were transplanted in the large cemented pots in field following Complete Randomized Design (CRD) in replicates of each treatment (Fig. 2). Water stress was imposed by water-withholding at late vegetative stage after 25 days after transplanting (DAT) while 
Table 1: Description of tomato genotypes used under study

\begin{tabular}{llll}
\hline S1. No. & Genotypes & Growth Type & Collection source \\
\hline 1 & EC249508 & Determinate & ICAR-NBPGR, New Delhi \\
2 & EC164677 & Determinate & ICAR-NBPGR, New Delhi \\
3 & EC 165690 & Determinate & ICAR-NBPGR, New Delhi \\
4 & EC160885 & Semi - determinate & ICAR-NBPGR, New Delhi \\
5 & EC179083 & Indeterminate & ICAR-NBPGR, New Delhi \\
6 & Arka Vikas & Semi - determinate & ICAR-IIHR, Bangalore \\
7 & Pusa Sadabahar & Determinate & ICAR-IARI, New Delhi \\
8 & Pusa Gaurav & Determinate & ICAR-IARI, New Delhi \\
9 & Pusa Rohini & Determinate & ICAR-IARI, New Delhi \\
\hline
\end{tabular}

control plants maintained well-watered. Pots in the water stress treatment were protected from any possible rain water by placing under rainout shelter. Observations of different morphological characters were recorded for three replicates of each genotype. Stress was relieved by re-watering and plants were maintained stress free till harvest. Various morphological characters were observed viz. days to $50 \%$ flowering, plant height, number of primary branches, number of flower truss per plant, number of flower per truss and fruit setting percentage. Quantitative data were statistical analyzed. A Student's t-test was performed to determine significant differences between control and drought treatment and differences among genotypes under both conditions (irrigated as well as drought stress) were analysed by one-way analysis of variance (ANOVA).

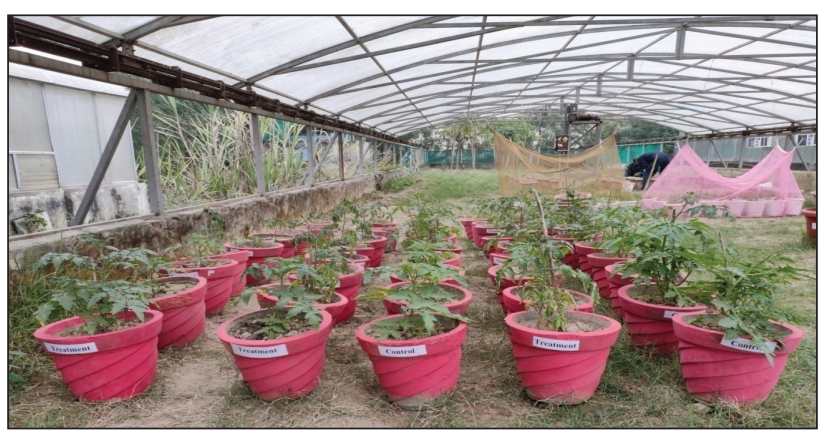

Fig. 2: Experimental field trial at research field under rain out shelter

\section{RESULTS AND DISCUSSION}

\section{Plant growth attributes}

Results of morphological characters viz. plant height and number of branches per plant are shown in
Table 2. Plant height of drought stressed plants were in the range of $59-132.67 \mathrm{~cm}$ while that of control plants ranged between $71-158.67 \mathrm{~cm}$ indicating a compelling reduction in plant height plant $^{-1}$ under water-stress in all the nine genotypes. Under wellwatered conditions genotype EC179083 $(158.67 \mathrm{~cm}$ \pm 3.21 ) recorded the maximum plant height plant $^{-1}$ while minimum plant height plant ${ }^{-1}$ was observed in Pusa Sadabahar $(71.67 \mathrm{~cm} \pm 1.53)$. Under waterstress condition again genotype EC179083 $(132.67 \mathrm{~cm}$ \pm 20.53 ) showed the maximum plant height plants $^{-1}$ while the minimum plant height plant $^{-1}$ was recorded in EC165690 $(59 \mathrm{~cm} \pm 3.61)$. The present results were in accordance with Zhou et al. (2017) who observed growth reduction in tomato cultivars height under water-stress conditions compared to controlled conditions. Elizabeth et al. (2018) also observed reduced plant height in drought conditions in comparison to well-watered conditions. They obtained results in the range of $77-75 \mathrm{~cm}$ for drought stressed plants. The results reported by EL-Mansy et al. (2021) also showed similar differences in plant height under abiotic stress. Blanchard-Gros et al. (2021) reported the impact of water-stress on plant height in tomato populations of Solanum chilense and Solanum lycopersicum. Water-stress impaired mitosis and cell elongation that resulted in poor growth (Hussain et al. 2008) and limited the cell growth processes largely due to the loss of turgor (Taiz and Zeiger 2010). Both the factors play an important role in growth reduction.

The number of branches plant ${ }^{-1}$ were in the range 8.67-19.00 in control plants where as the value for drought stressed plants ranged between 7.00-15.00. So the observations showed compelling reduction in branches plant ${ }^{-1}$ under water-stress conditions in all 
Table 2: Variations in morphological characters of nine tomato genotypes exposed to drought stress

\begin{tabular}{|c|c|c|c|c|}
\hline \multirow{3}{*}{$\begin{array}{l}\text { Characters } \rightarrow \\
\text { Genotypes } \downarrow\end{array}$} & \multicolumn{2}{|c|}{ Plant Height (cm) } & \multicolumn{2}{|c|}{ Number of Branches Plant ${ }^{-1}$} \\
\hline & Control & \multirow[t]{2}{*}{ Drought } & Control & Drought \\
\hline & Mean & & Mean & Mean \\
\hline EC249508 & $120.00 \pm 5.00$ & $82.00 \pm 6.08$ & $9.00 \pm 1.00$ & $7.00 \pm 1.00$ \\
\hline EC164677 & $139.00 \pm 5.29$ & $114.00 \pm 6.00$ & $10.33 \pm 1.53$ & $8.33 \pm 0.58$ \\
\hline EC 165690 & $72.67 \pm 5.03$ & $59.00 \pm 3.61$ & $13.33 \pm 2.08$ & $10.67 \pm 1.53$ \\
\hline EC160885 & $132.00 \pm 20.66$ & $99.67 \pm 13.05$ & $11.00 \pm 2.00$ & $7.67 \pm 1.15$ \\
\hline EC179083 & $158.67 \pm 3.21$ & $132.67 \pm 20.53$ & $8.67 \pm 1.53$ & $7.33 \pm 1.15$ \\
\hline Arka Vikas & $85.33 \pm 4.51$ & $79.67 \pm 4.51$ & $17.67 \pm 2.52$ & $14.67 \pm 1.53$ \\
\hline Pusa Sadabahar & $71.67 \pm 1.53$ & $64.33 \pm 4.04$ & $19.00 \pm 2.65$ & $15.00 \pm 2.65$ \\
\hline Pusa Gaurav & $78.33 \pm 2.08$ & $69.33 \pm 5.03$ & $14.67 \pm 2.52$ & $12.00 \pm 2.00$ \\
\hline Pusa Rohini & $98.67 \pm 4.04$ & $69.33 \pm 5.51$ & $13.33 \pm 2.08$ & $10.67 \pm 2.52$ \\
\hline Mean & $106.26 \pm 5.71$ & $85.56 \pm 7.60$ & $13.00 \pm 1.99$ & $10.37 \pm 1.57$ \\
\hline C.V.\% & 5.37 & 8.88 & 15.30 & 15.11 \\
\hline CD@5\% & 10.43 & 12.26 & 2.60 & 2.13 \\
\hline $\mathrm{SE}(\mathrm{d})$ & 2.34 & & 0.51 & \\
\hline CI 95\%(d) & $15.96-25.45$ & & $1.59-3.67$ & \\
\hline
\end{tabular}

the nine genotypes. Under well-watered conditions genotype Pusa Sadabahar $(19 \pm 2.65)$ recorded the maximum branches plant ${ }^{-1}$ while minimum branches plant ${ }^{-1}$ was recorded in EC179083 (8.67 \pm 1.53). Under water-stress conditions also genotype Pusa Sadabahar $(15 \pm 2.65)$ showed the maximum branches plants ${ }^{-1}$ while the minimum branches plant $^{-1}$ was recorded in EC249508 $(7 \pm 1.00)$. In general the number of branches per plant under drought stress was lesser than that of control. The differences within the genotypes may be due to the genetic composition. Varied supply of water also affects the number of branches per plant. Results reported by Ilakiya et al. (2017) showed observations on branching in the range of 13.30-20.00 in 100\% field capacity (FC) where as in 50\% FC observations were in the range of 12.31-17.36. Similarly Parveen et al. (2019) reported the less number of branches plant $^{-1}$ in drought condition (5.33-14.33) as compared to control conditions (7.33-19).

In all the nine genotypes, a reduction was observed in plant growth attributes under water stress conditions as compared to control (normal irrigation). When this decrease was compared in terms of percent reduction within the various genotypes (Fig. 3), Arka Vikas was found to perform the best among all under stress conditions followed by EC179083.

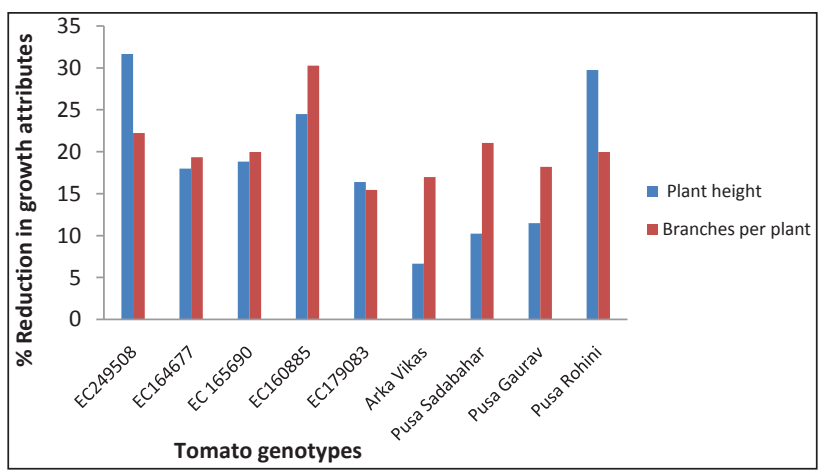

Fig. 3: Percent reduction in plant growth attributes of tomato genotypes under water stress conditions

\section{Yield attributes}

The data on yield attributing characters of nine tomato genotypes is presented in Table 3. The days to $50 \%$ flowering were in the range of $31-48$ days under controlled conditions while 28-38 days under drought conditions. Under control conditions, among all genotypes Pusa Gaurav took maximum number of days (48 days) for $50 \%$ flowering while genotypes EC179083 took minimum number of days (31 days). In controlled conditions observations of present study were in accordance to Khaled et al. (2015) which showed a period of 37-42 days for $50 \%$ flowering. Under drought conditions also Pusa Gaurav (38 days) showed maximum number of days taken for $50 \%$ flowering among all genotypes 
Impact of water-stress on plant growth and yield attributes in tomato genotypes

Table 3: Variations in yield attributing characters of nine tomato genotypes exposed to drought stress

\begin{tabular}{|c|c|c|c|c|c|c|c|c|}
\hline \multirow{2}{*}{$\begin{array}{l}\text { Characters } \rightarrow \\
\text { Genotypes } \downarrow\end{array}$} & \multicolumn{2}{|c|}{ Days to $50 \%$ flowering } & \multicolumn{2}{|c|}{ Number of Flower truss ${ }^{-1}$} & \multicolumn{2}{|c|}{$\begin{array}{c}\text { Number of flower truss } \\
\text { Plant }^{-1} \\
\end{array}$} & \multicolumn{2}{|c|}{ Fruit Setting \% } \\
\hline & Control & Drought & Control & Drought & Control & Drought & Control & Drought \\
\hline EC249508 & $41.67 \pm 5.69$ & $31.33 \pm 3.51$ & $7.33 \pm 0.58$ & $5.33 \pm 0.58$ & $32 \pm 3.61$ & $26.00 \pm 3.61$ & $45.24 \pm 14.87$ & $31.11 \pm 10.18$ \\
\hline EC164677 & $44.67 \pm 3.51$ & $36.00 \pm 2.65$ & $7.33 \pm 0.58$ & $6.33 \pm 0.58$ & $20.67 \pm 2.08$ & $17.67 \pm 1.53$ & $31.55 \pm 5.15$ & $26.19 \pm 8.58$ \\
\hline EC179083 & $31.33 \pm 1.53$ & $28.33 \pm 1.53$ & $7.67 \pm 0.58$ & $6.67 \pm 0.58$ & $20.33 \pm 2.08$ & $18.00 \pm 2.00$ & $26.19 \pm 2.06$ & $24.60 \pm 6.87$ \\
\hline Arka Vikas & $33.67 \pm 2.52$ & $29.33 \pm 2.08$ & $6.67 \pm 0.58$ & $6.33 \pm 0.58$ & $24.33 \pm 2.52$ & $22.00 \pm 2.65$ & $30.16 \pm 2.75$ & $25.40 \pm 15.12$ \\
\hline Pusa Sadabahar & $36.00 \pm 2.65$ & $30.00 \pm 1.00$ & $7.33 \pm 0.58$ & $6.67 \pm 0.58$ & $27.00 \pm 2.00$ & $23.33 \pm 2.52$ & $54.17 \pm 10.15$ & $40.48 \pm 10.91$ \\
\hline Pusa Gaurav & $47.67 \pm 2.52$ & $38.33 \pm 5.13$ & $8.00 \pm 1.00$ & $6.67 \pm 1.15$ & $25.33 \pm 4.73$ & $21.67 \pm 4.51$ & $33.13 \pm 4.47$ & $25.00 \pm 8.33$ \\
\hline CD@5\% & 5.24 & 3.49 & 0.84 & 0.88 & 4.02 & 3.98 & 9.52 & 9.52 \\
\hline $\mathrm{SE}(\mathrm{d})$ & 0.94 & & 0.18 & & 0.85 & & 2.43 & \\
\hline CI 95\%(d) & $5.51-9.31$ & & $0.86-1.58$ & & $1.98-5.42$ & & $2.99-12.86$ & \\
\hline
\end{tabular}

where as genotype EC179083 showed minimum period (28 days). This early flowering under drought may be attributed to rapid phenological development in order to complete the life cycle under unfavourable environmental conditions. Maximum change in days for 50\% flowering under two conditions was observed in EC160885 (11 days) while the minimum change was recorded in EC179083 (3 days). Results were in agreement with the observations of Sivakumar and Srividhya (2016), where they reported 4 days earlier flowering in drought-stressed plants than control plants.

The number of flower truss ${ }^{-1}$ (Table 3) were in the range of 5.33-6.67 in drought stressed plants while control plants showed a range of 6.67-8.00 suggesting a compelling reduction in number of flower truss ${ }^{-1}$ under water-stress conditions in all the nine genotypes. Under well-watered conditions, genotype Pusa Gaurav recorded the maximum $(8 \pm$ 1.00) number of flower truss ${ }^{-1}$, while minimum (6.67 \pm 0.58 ) number of flower truss $^{-1}$ was recorded in Arka Vikas. However under water-stress conditions genotype Pusa Sadabahar $(6.67 \pm 0.58)$ showed the maximum number of flower truss ${ }^{-1}$ and minimum number of flower truss ${ }^{-1}$ were recorded in EC249508 (5.33 \pm 0.58$)$. Earlier reports of Ilakiya et al. (2017) were also in conformity to present results where observations on number of flower truss ${ }^{-1}$ were in the range of $4.56-6.89$ in $100 \%$ FC and $4.13-5.92$ in 50\%
FC. Findings of Parveen et al. (2019) also showed that number of flower truss ${ }^{-1}$ varied from 4.33-7.33 under control conditions while under drought stress condition, it varied from 2.00-4.33. Among all the nine genotypes studied least difference for number of flower truss ${ }^{-1}$ was found in genotype Arka Vikas while Pusa Gaurav seemed to be most affected showing maximum difference under two conditions.

The number of flower truss plant ${ }^{-1}$ (Table 3 ) were in the range of 16.00-26.00 in drought stressed plants while in control plants the value ranged between 20.33-32.00 showing a clear compelling reduction in number of flower truss plant ${ }^{-1}$ under water-stress conditions in all the nine genotypes. Under well-

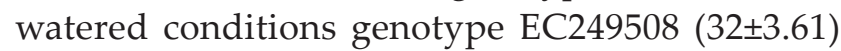
recorded the maximum number of flower truss plant $^{-1}$, while minimum number of flower truss plant $^{-1}$ was recorded in EC179083 (20.33 \pm 2.08$)$. Under water-stress conditions again genotype EC249508 (26 \pm 3.61$)$ showed the maximum number of flower truss plant ${ }^{-1}$ but minimum number of flower truss plant ${ }^{-1}$ was recorded in EC160885 (16.33 \pm 3.21$)$. Results were well in accordance with those of Ilakiya et al., (2017) whose observations were in the range of 19.39-29.00 and 13.33-20.00 for $100 \%$ FC and 50\% FC, respectively.

Fruit setting percentage plant ${ }^{-1}$ (Table 3) was in the range of $21.43 \%-40.48 \%$ in drought stressed 
plants while for control plants it was in the range of $26.19 \%-54.17 \%$, thus again indicating a reduction in fruit setting percentage under water-stress conditions in all the nine genotypes. Under well-watered conditions genotype Pusa Sadabahar $(54.17 \pm 10.15)$ recorded the maximum fruit setting percentage while minimum fruit setting percentage was recorded in EC179083 (26.19 \pm 2.06$)$. For water-stress conditions also, genotype Pusa Sadabahar $(40.48 \pm 10.91)$ showed the maximum fruit setting percentage but the minimum fruit setting percentage was recorded in Pusa Rohini (21.43 \pm 10.38$)$. Wahb-Allah et al. (2011) also reported a higher fruit setting percentage (56\%) under control condition in comparison to drought conditions (46\%). Similarly findings of Parveen et al. (2019) also observed that fruit setting percentage varied from $7.01 \%-48.14 \%$ under control conditions while under drought stress conditions it varied from $2.86 \%-43.85 \%$. Our observation also confirms that fruit setting percentage in all the genotypes was higher in control plants than stressed ones.

Comparison of percent reduction under water stress conditions in different yield attributes for nine genotypes is shown in Fig. 4. The results clearly indicated that minimum reduction was experienced in Arka Vikas and EC179083. Arka Vikas is a released variety and known for its thermal and moisture resistance thus performs good under water stress conditions, but EC179083 is still unexplored.

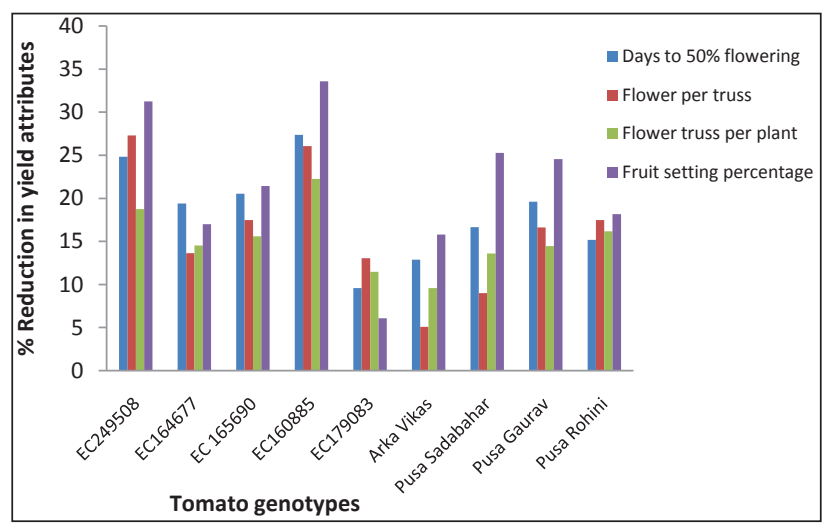

Fig. 4: Percent reduction in yield attributes of tomato genotypes under water stress conditions

Our results suggested that its performance under water stress conditions was at par with Arka Vikas, thus further studies or trials in this direction must be conducted to release it as a variety suitable for drought prone areas.

\section{CONCLUSION}

It can be concluded that tomato genotypes could respond differently against drought stress to enhance their ability to combat with adverse conditions. It is possible that morphological traits such as such as plant height, days to $50 \%$ flowering, number of flower truss ${ }^{-1}$, number of flower truss plant ${ }^{-1}$ and fruit setting percentage could be altered in a way that make plants better adapted to drought conditions and help in completing phenological development within short time to complete the life cycle under unfavourable environmental conditions. This variation could be used as an effective mechanism for drought tolerance. Results demonstrated that on the basis of morphological parameters, which are very useful tools in initial screening of drought tolerance, tomato genotypes Arka Vikas and EC179083 showed a promise for drought resistance.

\section{ACKNOWLEGEMENTS}

The first author sincerely thanks the Head, Department of Biotechnology, College of Agriculture, Sardar VallabhBhai Patel University of Agriculture and Technology, Meerut-250110 for providing facilities to accomplish the work.

\section{REFERENCES}

Bartels, D. and Sunkar, R. 2005. Drought and salt tolerance in plants. Crit. Rev. Plant Sci., 24: 23-58.

Blanchard-Gros, R., Bigot, S., Martinez, J.-P., Lutts, S., Guerriero, G. and Quinet, M. 2021. Comparison of drought and heat resistance strategies among six populations of Solanum chilense and two cultivars of Solanum lycopersicum. Plants, 10: 1720.

Bot, A.J., Nachtergaele, F.O. and Young, A. 2000. Land resource potential and constraints at regional and country levels. World Soil Resources Reports No. 90, pp.114, FAO, Rome (Pub). ISSN: 0532-0488.

Cantore, V., Lechkar, O., Karabulut, E., Sellami, M.H., Albrizio, R., Boari, F., Stellacci, A.M. and Todorovic, M. 2016. Combined effect of deficit irrigation and strobilurin application on yield, fruit quality and water use efficiency of "cherry" tomato (Solanum lycopersicum L.). Agric. Water Manage., 167: 53-61.

Elizabeth, N., Thomas, B. and Thouseem, N. 2018. Evaluation of tomato (Solanum lycopersicum L.) genotypes under water stress based on yield and physiological parameters. Int. J. Curr. Microbiol. App. Sci., 7(1): 214-225.

EL-Mansy, A.B., Abd El-Moneim, D., Alshamrani, S.M., Alsafhi, F.A., Abdein, M.A. and Ibrahim, A.A. 2021. Genetic diversity analysis of tomato (Solanum lycopersicum L.) with 
morphological, cytological, and molecular markers under heat stress. Horticulturae, 7(4): 65.

Fahad, S., Bajwa, A.A., Nazir, U., Anjum, S.A., Farooq, A., Zohaib, A., Sehrish, S., Wajid, J., Steve, A., Shah, S., Muhammad, I., Hesham, A., Chao, W., Depeng, W. and Jianliang, H. 2017. Crop production under drought and heat stress: plant responses and management options. Front. Plant Sci., 8: 1147.

FAOSTAT. 2020. Available at: http://www.fao.org/faostat/ en/\#home

Gerster, H. 1997. The potential role of lycopene for human health. J. Am. Coll. Nutr., 16: 109-126.

Hussain, M., Malik, M.A., Farooq, M., Ashraf, M.Y. and Cheema, M.A. 2008. Improving drought tolerance by exogenous application of glycinebetaine and salicylic acid in sunflower. J. Agron. Crop Sci., 194: 193-199.

Ilakiya, T., Premalakshmi, V., Arumugam, T. and Sivakumar, T. 2019. Screening of tomato (Solanum lycopersicum L.) hybrids with their parents for various growth related parameters under drought stress. J. Pharmacog. Phytochem., 8(3): 3845-3848.

Khaled, M., Sikder, S., Islam, M.R., Hasan, M.A. and Bahadur, M.M. 2015. Growth yield and yield attributes of tomato (Lycopersicon esculentum Mill.) as Influenced by indole acetic acid. J. Environ. Sci., Natural Resources, 8(1): 139-145.

Li, Y., Wang, H., Zhang, Y. and Martin, C. 2018. Can the world's favourite fruit, tomato, provide an effective biosynthetic chassis for high-value metabolites?. Plant Cell Rep., 37(10): 1443-1450.

Nankishore, A. and Farrell, A.D. 2016. The response of contrasting tomato genotypes to combined heat and drought stress. J. Plant Physiol., 202: 75-82.

Nuruddin, M.M., Madramootoo, C.A. and Dodds, G.T. 2003. Effects of water stress at different growth stages on greenhouse tomato yield and quality. HortScience. 38(7): 1389-1393.

Parveen, A., Rai, G.K., Mushtaq, M., Singh, M., Rai, P.K., Rai, S.K. and Kundoo, A.A. 2019. Deciphering the morphological, physiological and biochemical mechanism associated with drought stress tolerance in tomato genotypes. Int. J. Curr. Microbiol. App. Sci., 8(5): 227-255.
Pereira, A. 2016. Plant abiotic stress challenges from the changing environment. Front. Plant Sci., 7: 1123.

Rai, G.K., Kumar R., Singh A. K., Rai P. K. Rai, M., Chaturvedi A.K. and Rai, A.B. 2012. Changes in antioxidant and phytochemical properties of tomato (Lycopersicon esculentum Mill.) under ambient condition. Pakistan J. Bot., 44: 667-670.

Raiola, A., Rigano, M.M., Calafiore, R., Frusciante, L. and Barone, A. 2014. Enhancing the health-promoting effects of tomato fruit for biofortified food. Mediators Inflammation, 2014:139873. DOI: 10.1155/2014/139873

Rivelli, A.R., Trotta, V., Toma, I., Fanti, P. and Battaglia, D. 2013. Relation between plant water status and Macrosiphum euphorbiae (Hemiptera: Aphididae) population dynamics on three cultivars of tomato. Eur. J. Entomol., 110: 617-625.

Sivakumar, R. and Srividhya, S. 2016. Impact of drought on flowering, yield and quality parameters in diverse genotypes of tomato (Solanum lycopersicum L.). Adv. Hort. Sci., 30(1): 3-11.

Taiz, L. and Zeiger, E. 2010. Plant Physiology. $5^{\text {th }}$ edition, Sinauer Associates, pp. 782.

Wahb-Allah, M.A., Alsadon, A.A. and Ibrahim, A.A. 2011. Drought tolerance of several tomato genotypes under greenhouse conditions. World Appl. Sci. J., 15(7): 933-940.

Zhou, R., Kong, L., Wu, Z., Rosenqvist, E., Wang, Y., Zhao, L., Zhao, T. and Ottosen, C.-O. 2019. Physiological response of tomatoes at drought, heat and their combination followed by recovery. Physiol. Plant, 165: 144-154.

Zhou, R., Yu, X., Ottosen, C.-O., Rosenqvist, E., Zhao, L., Wang, Y., Yu, W., Zhao, T. and Wu, Z. 2017. Drought stress had a predominant effect over heat stress on three tomato cultivars subjected to combined stress. BMC Plant Biol., 17(1): 24. 
